\title{
BMJ Open Epidemiology of race day injury in young professional jockeys in Great Britain from 2007 to 2018: a retrospective cohort study
}

\author{
Madeleine Davies (D) ,, ${ }^{1,2}$ Kate A Jackson, ${ }^{3,4}$ Anna Louise Mackinnon,, 3 \\ Alison Turner, ${ }^{6}$ Kerry Kuznik, ${ }^{3,7}$ Jerry Hill, ${ }^{7}$ Julia L Newton,, \\ Maria Sanchez Santos (1) ${ }^{8}$
}

To cite: Davies M, Jackson KA, Mackinnon AL, et al. Epidemiology of race day injury in young professional jockeys in Great Britain from 2007 to 2018: a retrospective cohort study. BMJ Open 2021;11:e044075. doi:10.1136/ bmjopen-2020-044075

- Prepublication history for this paper is available online. To view these files, please visit the journal online (http://dx.doi. org/10.1136/bmjopen-2020044075).

Received 21 August 2020 Accepted 21 July 2021
Check for updates

(C) Author(s) (or their employer(s)) 2021. Re-use permitted under CC BY-NC. No commercial re-use. See rights and permissions. Published by BMJ.

For numbered affiliations see end of article.

Correspondence to Dr Madeleine Davies; m.davies@bath.ac.uk

\section{ABSTRACT}

Introduction There are limited injury data in professional horse racing, particularly by sex.

Objectives To describe injury incidence, characteristics and falls in male and female, flat and jump jockeys in Great Britain.

Design and setting Retrospective cohort study of professional jockeys in Britain.

Participants 245 jockeys licensed between 2007 and 2017.

Primary and secondary outcome measures The primary outcome measure was injury on a race day. Injury incidence (per 1000 rides; per 1000 falls) was derived. Incidence-rate ratios (IRR) were calculated to compare incidence between flat and jump racing, male and female jockeys, and male flat and male jump jockeys for: (i) injury incidence, (ii) fall incidence and (iii) injuries per fall. Results 234 British professional jockeys were included. Jockeys were on average $19.5 \pm 2.0$ years old at licence date, $79.9 \%$ male and $58.1 \%$ flat. The time of followup (racing in the study) was $3.7(S D=2.3)$ years. There were 278 injuries, occurring in-race $(81.7 \%)$, in the stalls $(10.8 \%)$ or parade ring $(6.1 \%)$. After one injury was removed to preserve anonymity, $57.2 \%$ were soft tissue injuries, $25.3 \%$ fractures and $10.5 \%$ concussion. There were 1634 falls, with $92 \%$ in male jump racing. The injury incidence was higher in jump racing (5.1 vs $1.0 / 1000$ jockey rides). The falls incidence was $1.8 / 1000$ rides in flat and $46.2 / 1000$ rides in jump racing (IRR $0.04,95 \% \mathrm{Cl} 0.03$ to 0.04 ). There were over five times higher injuries/1000 falls in flat than jump racing (IRR $5.56,95 \% \mathrm{Cl} 4.05$ to 7.53). Male flat jockeys fell less than female flat (IRR 0.57 , $95 \% \mathrm{Cl} 0.35$ to 0.97 ).

Conclusion Most injuries occurred in-race and were soft tissue injuries. Jump jockeys fell more often than flat, and female flat jockeys fell more often than male flat. Flat jockeys injured more frequently when falling. No sex differences were seen for injuries per fall.

\section{INTRODUCTION}

Professional horse-racing in Great Britain (GB) is an industry worth more than $£ 4$ billion annually and employing over 20000 staff. ${ }^{1}$ Employment as a professional jockey
Strengths and limitations of this study

- This study is the first to report in-race injury rates in male and female, jump and flat jockeys across Great Britain.

- These data are representative of all British jockeys licensed between July 2007 and November 2017

- Jockeys observed from the point of licensing may be younger, fitter and more recently fall-trained than all professional jockeys irrespective of license date, and therefore these injury data may not be representative of all current professional jockeys.

- As there are multiple races per day in horseracing, injuries could not be matched with certainty to a specific race and were therefore matched by race day.

- As each injury was matched by day, we are unable to differentiate between concomitant injuries in one race or in two separate races on one day.

carries a risk of injury that can be severe and career ending, with associated financial consequences for the jockey and industry. ${ }^{2}$ Therefore, understanding the epidemiology of injury in jockeys provides important information to jockeys, physiotherapists and medical staff and the broader racing industry, to inform strategies to reduce injury risk, ensure optimal readiness for participation and support the planning of medical and financial support for injured jockeys.

In GB, professional jockeys are insured with the Professional Riders Insurance Scheme (PRIS), and professional horseracing is categorised into flat and National Hunt (jump) racing, Nearly $50 \%$ of PRIS claims are for fractures, ${ }^{2}$ while jump racing injuries are responsible for the majority of insurance claims. There have been efforts to describe injury epidemiology and risk factors in horseracing, most recently in countries such as the USA, 
New Zealand and Australia. ${ }^{3-13}$ A recent study in Ireland by O'Connor et al found that there had been a significant increase in injuries per 1000 falls and falls per 1000 rides in jump jockeys when comparing injury incidence prior to 2006, to those from 2011 to $2015 .{ }^{14}$ The most recent GB jockey injury data were published over 15 years ago ${ }^{15}$ and may not reflect changes to the sport's organisation and novel athlete initiatives which have been developed in this time. Mandatory residential courses at the point of jockey licensing in GB have been developed (7-day course from 2000 onwards, 14-day residential course from January 2017) to: embed fitness assessments, diet and nutrition training, sports science awareness, rule and regulation information and riding work. This programme of training also includes falls training and simulated assessments at the point of licensing. To date, there has been a limited research focus on recently licensed professional jockeys. A formal licensing process and residential course may, however, provide intervention opportunities as jockeys are obtaining their professional license to better prepare them for a professional career in racing. Detailed, current epidemiological injury data are required to identify prominent injury types and characteristics which can become targeted prevention opportunities.

The aim of this study is to describe injury incidence over an 11-year period in a sample of young professional male and female, flat and jump jockeys in British horse racing. Secondary aims were to describe injury type, location, severity (time loss) and performance (falls and wins) in GB horseracing.

\section{METHODS}

\section{Study design, setting and participants}

Using a retrospective cohort study design, a sample of 245 professional jockeys were selected. Eligibility was defined as a jockey who was licensed as a professional jockey for the first time between July 2007 and November 2017. ${ }^{16}$ Eligibility (licensing) was achieved after attendance at a licensing course at either the British Racing School or National Horseracing College (formerly Northern Racing College) or via the British Horseracing Authority. The cohort was therefore jockeys beginning their professional career, and data were extracted from that point onwards.

\section{Variables and data sources}

Since 1992, it has been compulsory for all incidents sustained on a licensed racetrack in GB to be reported to the Racecourse Medical Official and recorded on one central database. Performance data are routinely collected in the industry. All injuries and performance data (rides, falls and wins) for eligible jockeys from license period until 1 July 2018 were extracted.

Injury data for each incident included: race location (GB and non-GB), body part, incident type, surface type (jump/flat), resolution (cleared to return) date, whether the injury is acute or recurrent and the outcome of the incident (health service provision required). Only injuries that were reported by the Medical Officer on a race day in GB (ie, not in Europe or internationally) were included $(n=278)$. Severe injury was defined by time loss duration (from racing), with 28 days or more between the injury date and resolution date considered as severe. ${ }^{17}$ In cases where a single incident resulted in more than one injury, each body part or injury type was counted as a separate injury. Body site of injury was grouped according the Orchard Sports Injury Classification System. ${ }^{18}$ Injuries during the study period were excluded from analysis if they occurred outside of GB, in races prior to professional licensing or as an amateur jockey. In-race injury incidence was estimated using only those injuries occurring specifically during a race exposure and not those occurring in the parade ring, stalls or between the parade ring and the start of the race.

Performance data available in Wetherby's performance records include race date, finishing position, surface type and data on non-completion of the race. Falls were derived from Wetherby's race non-completion data, using the categories 'fell', 'slipped up', 'brought down' and 'unseated rider'. The Strengthening the Reporting of Observational Studies in Epidemiology (STROBE) guidelines were used to report methods and findings. ${ }^{19}$ This study was performed in accordance with the 1964 Declaration of Helsinki ethical standards.

\section{Patient and public involvement}

Patient and public involvement was undertaken for this study. A forum was organised with former jockeys, trainers and project stakeholders to establish the overarching grant's aims and work packages, of which this article is one deliverable. Two former professional jockeys, and a lay representative, resided on the study steering group throughout. Therefore, there was involvement of these groups in developing research questions and outcome measurements, study design and processes, and informing the study's recruitment strategy and reporting of findings.

\section{Statistical methods}

All analyses were conducted using Stata V.15 statistical software (Stata, College Station, Texas, USA). Descriptive statistics (mean (SD) for continuous variables and number (percentage) for categorical variables were used to describe demographic, performance (wins) and injury data. The injury incidence (number of injuries per 1000 rides and falls) and number of falls and wins per 1000 rides during racing and their $95 \%$ CI were calculated. All results are presented separately for male and female and for flat and jump jockeys. Incidencerate ratios (IRR) and 95\% CI were calculated for flat and jump, male and female flat jockeys and male flat compared with male jump jockeys.

\section{RESULTS}

\section{Professional jockey cohort characteristics}

Two hundred and forty-five professional jockeys (90968 rides), who received a British professional license between 


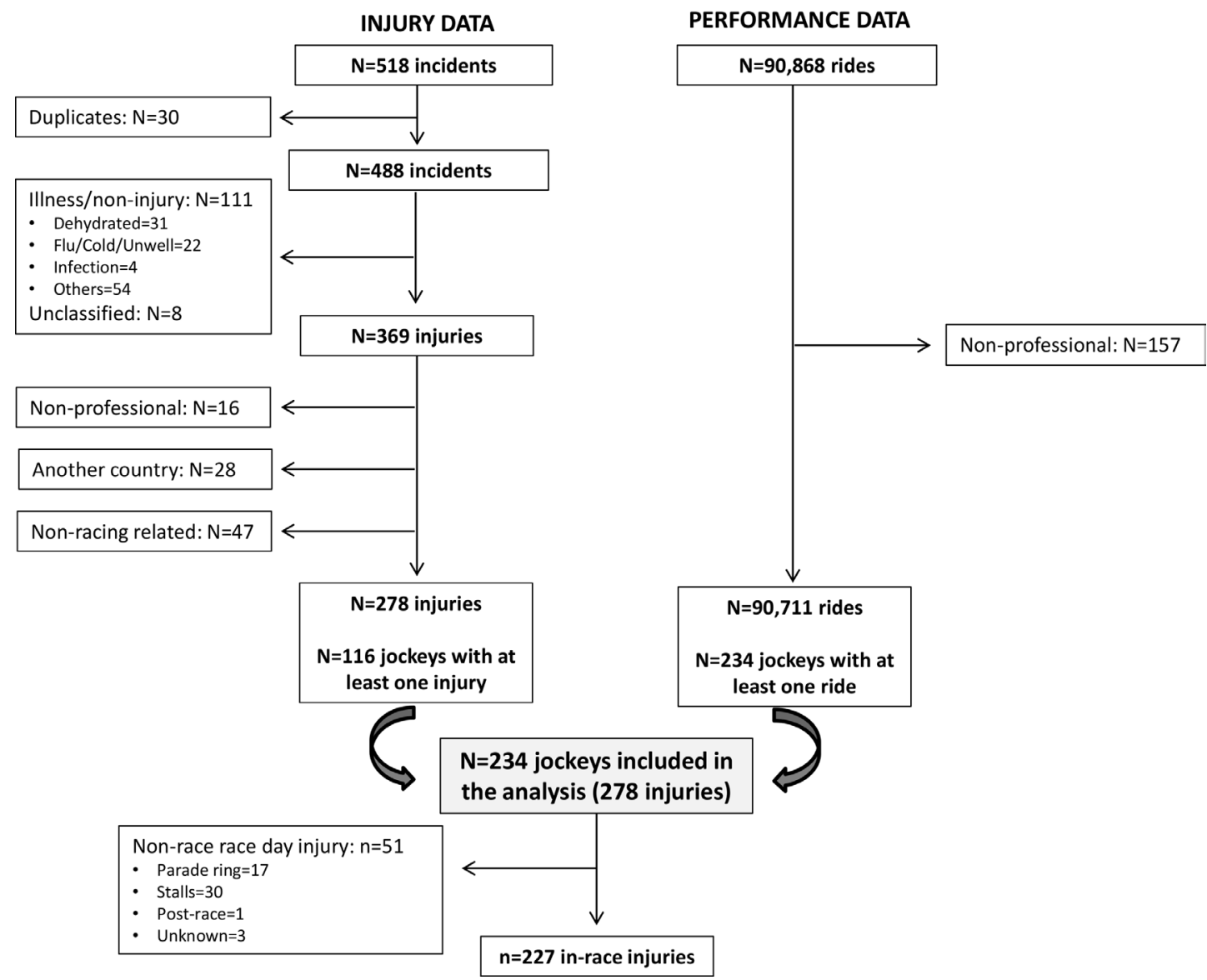

Figure 1 Participant flow from injury data and performance data, to cohort of recently licensed professional jockeys with at least one ride during the study period.

July 2007 and November 2017, were eligible for inclusion in the study. Professional jockeys with at least one GB professional race (figure 1) were retained $(n=234 ; 90711$ rides),with an average time of follow-up (professionally racing in the study) of $3.7(\mathrm{SD}=2.3)$ years. Jockeys had a mean age at license date of 19.5 years $( \pm 2.0)$, and 47 $(20.1 \%)$ were female (table 1$)$. Jump jockeys comprised $41.9 \%$ of the sample; and $33.1 \%$ of flat jockeys and $2.0 \%$ of jump jockeys were female.

\section{Injuries}

Two hundred and seventy-eight race-related injuries were recorded over the study period, 175 of which were in jump racing $(62.9 \%)$ and $103(37.1 \%)$ of which were in flat racing. One female jump injury was recorded in

\begin{tabular}{|c|c|}
\hline Characteristic, n (\%) & $\mathrm{N}=234$ \\
\hline \multicolumn{2}{|l|}{ Sex, n (\%) } \\
\hline Male & $187(79.9)$ \\
\hline Female & $47(20.1)$ \\
\hline \multicolumn{2}{|l|}{ Type of surface, n (\%) } \\
\hline Flat & $136(58.1)$ \\
\hline Jump & 98 (41.9) \\
\hline
\end{tabular}

the study period; therefore, this injury has been removed from type and severity (table 2), to maintain confidentiality. However, this injury was retained for incidence analysis, as performance data is not restricted and is freely available.

Soft tissue was the most common injury type $(57.4 \%)$, followed by fractures $(25.3 \%)$, concussions $(10.5 \%)$, lacerations $(4.7 \%)$ and dislocations $(1.8 \%)$. One injury $(0.4 \%)$ was recorded as unclassified. Over a third of injuries were severe in time loss duration $(35.0 \%)$, and the median time loss from all severe injuries was 60 days (IQR: 40-128). A higher proportion of injuries were severe in duration for jump racing $(40.8 \%)$ than in flat racing $(25.2 \%)$. Soft tissue injuries were the most prevalent injury type across male flat, female flat and male jump racing. For male flat and male jump racing, the next prominent injury type was fracture (table 2). However, for female flat racing, concussion was the second most prevalent injury, followed by lacerations (table 2), while no female flat jockeys sustained a fracture during the study period. The greatest time loss injuries were fractures $(\mathrm{n}=70)$, with a median time loss of 47.5 days, followed by dislocations $(n=5)$ with a median time loss of 47 days. The majority of fractures $(73.7 \%)$ were severe in time loss duration. The least severe injuries for time loss were lacerations (3 days), and soft tissue injuries (4days). 
Table 2 Type and severity of injuries occurring in flat, jump, male and female, young professional jockeys between 2007 and 2018 ( $n=278$ injuries; $n=277$ once excluding female jump jockey)

\begin{tabular}{|c|c|c|c|c|c|c|}
\hline & \multicolumn{3}{|l|}{ Flat $(n=103)$} & \multirow{2}{*}{$\begin{array}{l}\text { Jump }(n=174) \\
\text { Male }\end{array}$} & \multirow[b]{2}{*}{ Total } & \multirow{2}{*}{$\begin{array}{l}\text { Time-loss* (days) } \\
\text { (Median, (IQR)) }\end{array}$} \\
\hline & Male $(n=86)$ & Female $(n=17)$ & All & & & \\
\hline \multicolumn{7}{|l|}{ Type of injuries, n (\%) } \\
\hline Fracture & $15(17.4)$ & $0(0.0)$ & $15(14.6)$ & 55 (31.6) & $70(25.3)$ & $47.5(25-87)$ \\
\hline Soft tissue & $56(65.1)$ & $11(64.7)$ & $67(65.1)$ & 92 (52.9) & $159(57.4)$ & $4(1-13)$ \\
\hline Concussion & $9(10.5)$ & $3(17.7)$ & $12(11.7)$ & $17(9.8)$ & $29(10.5)$ & $24(14-38)$ \\
\hline Dislocation & $1(1.2)$ & $0(0.0)$ & $1(0.1)$ & $4(2.3)$ & $5(1.8)$ & $47(41-78)$ \\
\hline Lacerations & $5(5.8)$ & $2(11.8)$ & $7(0.7)$ & $6(3.5)$ & $13(4.7)$ & $3(2-16)$ \\
\hline Unclassified & $0(0.0)$ & $1(5.9 \%)$ & $1(0.1 \%)$ & $0(0.0)$ & $1(0.4)$ & 235 (235-235) \\
\hline \multicolumn{7}{|l|}{ Severe injuries, n (\%) } \\
\hline 28 or more days-loss & $21(24.4)$ & $5(29.4)$ & $26(25.2)$ & $71(40.8)$ & $97(35.0)$ & $60(40-128)$ \\
\hline
\end{tabular}

Results expressed as number (\%).

*3 injuries did not resolve during the study period.

The proportion of soft tissue injuries was lower in-race than in stalls and/or parade ring $(52.0 \%$ vs $81.3 \%)$, and higher proportion of concussion and fractures occurred in-race compared with in the stalls/parade ring (concussion: $12.3 \%$ vs $2.1 \%$; Fracture: $28.6 \%$ vs $10.4 \%$ ).

\section{Injury incidence, falls and wins per $\mathbf{1 0 0 0}$ rides}

Of the number of rides in the performance dataset over the study period, 57429 (63.3\%) were in flat racing. There were 1634 falls in the 90711 races, of which 1539 (94.2\%) were in jump racing (table 3 ). The overall in-race injury incidence in professional horse racing was 2.5 (95\% CI 2.2 to 2.9 ) injuries per 1000 jockey rides, 1.0 (95\% CI 0.8 to 1.3 ) in flat racing and 5.1 (95\% CI 4.3 to 5.9) per 1000 rides in jump racing, representing an IRR of 0.20 (95\% CI 0.14 to 0.27 ) for flat versus jump racing. The injury incidence was significantly lower for male flat jockeys than for male jump jockeys (IRR 0.18 , 95\% CI 0.13 to 0.26 ). There were no statistically significant differences in injury incidence between male flat ( 0.94 injuries per 1000 rides) and female flat jockeys (1.42 injuries per 1000 rides (IRR $0.66,95 \%$ CI 0.34 to 1.37$)$ ).

Falls were significantly more common in jump than flat racing, with an incidence of 46.24 falls per 1000 rides in jump racing and 1.77 falls per 1000 rides in flat racing, representing an IRR of 0.04 (95\% CI, 0.03 to 0.04 ) in flat versus jump racing (table 3 ). There was a sex difference in falls per 1000 rides, with female flat jockeys significantly more likely to fall (2.61 falls per 1000 rides), than male flat jockeys ( 1.55 falls per 1000 rides), representing an IRR of 0.66 (95\% CI 0.44 to 10.10) in male flat versus female flat.

The overall injury rate per 1000 falls was 138.9; however, this was significantly higher in flat racing $(610.5 / 1000$ falls) than for jump racing (109.8/1000 falls), representing an IRR of 5.56 (95\% CI 4.05 to 7.53 ) in flat versus jump racing (table 3 ). There were no statistically significant sex differences in injury rate per fall between male and female flat jockeys (IRR $1.16,95 \%$ CI 0.60 to 2.40).

Overall, there were 97.9 wins per 1000 rides, with 95.0 wins per 1000 rides in flat racing and 102.8 wins per 1000 rides in jump racing. There was a higher rate of wins in flat male than flat female jockeys (IRR 1.15, 95\% CI 1.07 to 1.25 ) (table 3 ).

\section{DISCUSSION}

This study is the first in GB to report in-race injury rates nationally by sex, in a defined sample of young, professional, flat and jump jockeys. Injury types were broadly similar between flat and jump jockeys; however, more injuries were classified as severe in jump than in flat racing. Injury incidence was higher in jump racing than flat racing; however, injury rate per fall was significantly higher in flat racing than jump racing. There were sex differences for fall incidence, pattern of injuries and wins per 1000 rides. Strengths of this study include the use of national data from official data sources for up to 11 years of professional racing (depending on license date), and these data being representative of young professional jockeys in GB for this period. This study is the first to our knowledge which has excluded none in-race injuries (parade ring, stalls, postrace) from incidence estimates and calculated in-race injury incidence for male and female jockeys. A significant limitation in sport epidemiology research, including in racing, is the paucity of data for female athletes. The presentation of data stratified by sex here is a strength of this analysis. Further strengths of this study include the duration of data collection, standardisation of data collection and the level of routine injury reporting on race days in GB, as reporting and recording these injuries are stipulated in racing regulations. 


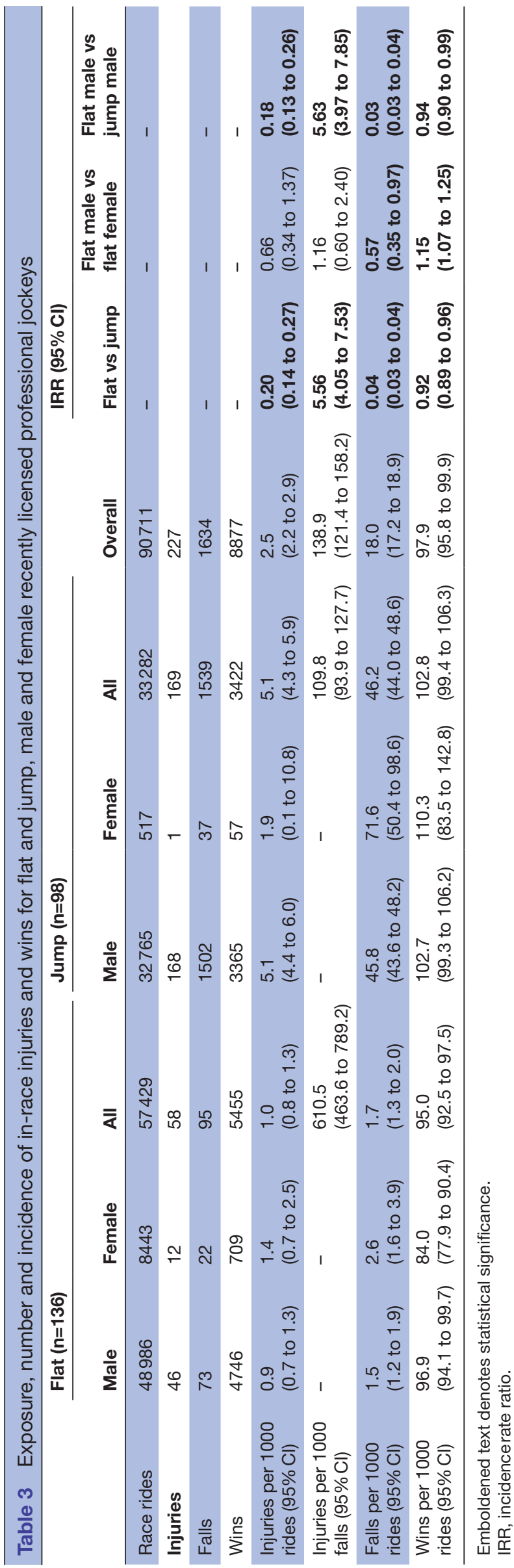

There are limitations regarding the generalisability of these results to the whole jockey population. This study is representative of professional jockeys from the point of licensing in GB. However, this younger (more recently falls trained and observed from the point of licensing) cohort of jockeys may not be representative of all current (older) male and female, professional flat and jump jockeys. There is the potential for younger jockeys to be fitter and potentially more recently fall-trained and therefore demonstrate less falls and injuries per fall. However, there may also be a survival effect, whereby jockeys sustaining professional careers may be those who are less likely to fall and have accumulated varied 'successful' (less injurious) falls experiences or are less likely to injure when falling. Furthermore, these associations may be confounded by their equine athlete pairings. Apprentice (newly licensed flat) and conditional (newly licensed jump) jockeys may ride less reliable horses, who could be at a higher risk of their own or jockey injuries. Recently, licensed jockeys may also make more errors in judgement resulting in horse falls or ride in lower grade races with more falls around them. Previous research has found experienced horses to have a lower falls incidence ${ }^{20}$ and horse age and race class to be suggestive of increased likelihood of equine catastrophic musculoskeletal injury. ${ }^{21}$ Unfortunately, we have limited horse data (ie, behaviour, age of horse, training, race load, horse injury) to support discussion of horse experience and reliability.

Injuries could not be matched with certainty to a specific race; therefore, we matched injury and performance data by day. Each injury was analysed in isolation, including any concomitant injuries in one race, or race day. We were able to match all injury dates to a race date, which is reassuring for data completeness in both datasets. The detailed level of data management is considered to be a strength of this analysis compared with other previous epidemiological studies. While this is the best data source available in GB for in-race injury capture, it may not include jockeys who sought care for these injuries in the days postrace and any jockeys who did not present with injury.

The most common injuries were similar to those described previously, ${ }^{15}$ with soft tissue injuries, fractures and concussion most common, and fractures the greatest time loss injuries. For female flat jockeys, concussion was the second most prevalent injury, followed by lacerations, with no fractures. However, for male flat jockeys, the second most common injury was fracture followed by concussion. Previous research has suggested the concussion rate to be broadly higher for flat than jump jockeys, although sex was not considered in this work. ${ }^{15}$ Periods of relative energy deficiency ${ }^{22}$ have been discussed in weight-restricted sports and are associated with changes in bone density, which might also suggest sex differences in fracture risk. Females may be more readily able to make weight categories, particularly as apprentice jockeys, in comparison with males where it has been suggested that making weight with minimal disruption to well-being may 
not be feasible. ${ }^{23}$ Previous research in this cohort has identified a very low bone density (defined as a z-score $<-2.0$ ), in $29 \%$ of male, flat jockeys but not in female jockeys. ${ }^{16}$ Future research in this area could expand on this relationship with fracture risk, particularly given the nature of $50 \%$ of PRIS claims being for fracture, ${ }^{2}$ and therefore the financial implications of fractures for the industry, as well as financially and functionally for jockeys.

Jump jockeys having a higher injury incidence than flat jockeys, and falling significantly more than flat jockeys, but flat jockeys being more likely to be injured when falling are consistent with previous studies. ${ }^{15} 18$ Our focus on true 'in-race' injuries could have contributed to a more conservative estimate of injury incidence. However, race day injuries in the stalls or parade ring are important and have therefore been included in table 2 , though excluded from incidence analyses. In other sports, warm-up injuries are considered separately to match injuries as these do not involve match exposure. ${ }^{24}$ It has been recommended in international consensus statements for reporting injury and illness in sporting environments that training and competition injury data should be reported separately, as there is often markedly different injury risk between these activities. ${ }^{25}$ For these reasons, we have focused on in-race injuries as those where jockeys are competitively exposed in competition with each other.

The higher injury incidence in jump racing is aligned with the majority of PRIS insurance claims being in jump racing $^{26}$ and may be contributed to by the challenges associated with jumping obstacles, becoming unbalanced and unseated or brought down by other horses and jockeys during these activities. These additional factors may also be associated with the higher severity of injury seen in jump racing. Given an awareness of upcoming obstacles, jump jockeys may be able to foresee and prepare for a fall if approaching an obstacle incorrectly or if another horse has already fallen in front of them. Navigating these obstacles also leads to slower racing speeds and a subsequent slower speed of falling in comparison with flat racing. These combined factors may contribute to reducing injury risk per fall. Conversely, flat jockeys generally travel at greater speeds, potentially with more runners per race, which may mean that their injuries are resultant of the fall itself and postfall circumstances. The higher injury rate per fall in flat jockeys may be associated with the number of competitors, the force of ground impact at speed, likelihood of trampling when fallen and reduced reaction time to employ fall techniques. The 'going' (racing surface) may additionally be affected by seasonality, with more jump racing in winter months, and flat racing in the summer, with a harder contact surface for any falls.

Female flat jockey fall rates $(2.6(1.6-3.9) / 1000$ rides $)$ were higher than male (1.5 (1.2-1.9)/1000 rides), which is consistent with previous research. ${ }^{27}$ In male flat and jump jockeys, fall rates were lower in our study than previous studies, with rates of 1.5 falls/1000 rides and 45.8 falls/1000 rides, respectively. GB data from 2002 found 4.2 falls $/ 1000$ rides and 68 falls $/ 1000$ rides, respectively, for male flat and jump jockeys, ${ }^{15}$ and an Australian study estimated 4.2 falls/1000 rides and 52.6/1000 rides, respectively. ${ }^{28}$ More recent data from Ireland reported 3.8 falls/1000 rides and 49.5 falls/1000 rides for flat and jump jockeys, respectively. ${ }^{29}$ It has been suggested that fall rates have decreased over recent years particularly in flat (4\% from 2005/2006 to 2017/2018) and also in hurdle racing (2\% from 2005/2006 to $2017 / 2018) .{ }^{20}$ Possible explanations for this discrepancy may be differences in the study population or methodological considerations. Turner $e t a l^{15}$ did not define a fall, and there is the potential for recorded falls to be at any point on a race day or more strictly between the start of a race and finishing post. O'Connor et al define a fall as 'the rider being dislodged from the horse, regardless of outcome' which is similar to our study. Using Wetherby fall data from all licensed UK racecourses, we included all unseated in a race category ('fell', 'slipped up', 'brought down' and 'unseated rider').

For young professional jockeys, recent interventions such as mandatory licensing courses, including falls training and simulated riding assessment, may have contributed to a reduced falling incidence over recent years, compared with prior studies. There have additionally been changes in horse racing organisation and practices, including jockey coaching from 2006, jockey coaches accreditation from 2011, improved turf management, improved personal protective equipment such as helmets and body protectors, the introduction of safety officers from 1985, improved fence and course design. While these will not all impact fall rate, they may influence the injury rate per fall and safety in the horseracing environment, in comparison with previously published research.

\section{CONCLUSION}

Young professional jump jockeys in GB have a higher in-race injury incidence and fall incidence than flat jockeys; however, flat jockeys had a far greater injury rate per fall. Flat and jump jockeys presented with similar injury types, but more injuries were classified as severe in jump than in flat racing. There were sex differences for fall incidence and injury type, which warrants further study. Future research in this population could be more mechanistic in nature and focus on the higher injury incidence and severity in jump racing and mitigating the higher injury rate per fall in flat racing.

\section{Author affiliations}

${ }^{1}$ Institute for Sport, Exercise and Health, University College London, London, UK ${ }^{2}$ Department of Health, University of Bath, Bath, UK

${ }^{3}$ Centre for Sport, Exercise and Osteoarthritis Research Verses Arthritis, University of Oxford, Nuffield Department of Orthopaedics Rheumatology and Musculoskeletal Sciences, Oxford, UK

${ }^{4}$ Sporting Knee Injury Prevention Programme (SKIPP), Headington, UK

${ }^{5}$ Injured Jockeys Fund, Newmarket, UK

${ }^{6}$ NIHR Oxford Biomedical Research Centre, Oxford, UK 
${ }^{7}$ British Horseracing Authority Ltd, London, UK

${ }^{8}$ Nuffield Department of Orthopaedics Rheumatology and Musculoskeletal Sciences, University of Oxford, Oxford, UK

Acknowledgements We would like to acknowledge the project funders and our project steering group for their sustained support throughout this grant. We would also like to acknowledge the athlete representatives, patient and public representatives and participants who have helped us to shape this project and directed us towards addressing valuable questions for jockeys and the industry. We would like to also acknowledge Dr Betsy Georgiou and Mr Aodhagan Conlon for proof-reading our final manuscript.

Contributors JLN, ALM, AT, KK, KAJ and JH contributed to the study conception and design and prepared and obtained project funding. AT, KAJ, KK and ALM obtained necessary data permissions. All authors provided project oversight, and KK and JH provided support regarding horse-racing queries. MSS, KAJ and MD prepared the draft versions and the final manuscript. ALM and KK collected and cleaned data, and MSS and MD prepared data for, and undertook, analyses. All authors reviewed and approved draft and final manuscripts.

Funding This research was supported by the British Horseracing Authority, the Professional Jockeys Association (PJA) and the Injured Jockey Fund (IJF). This work was also supported by the Racing Foundation (grant number HFR00920), the British Association of Sport and Exercise Medicine (grant number HFR00840) and the Centre for Sport, Exercise and Osteoarthritis Research Versus Arthritis (Grant reference 21595).

Competing interests MD has received project funding from the Rugby Football Union, Rugby Football Union's Injured Players Foundation, British Medical Association and British Horseracing Association. Since submitting this manuscript, MD has become a sessional employee of the British Horseracing Authority, supporting the COVID-19 response in racing. KK has no competing interests. After completing her academic contract on this study, KK has commenced employment in the Medical Department of the British Horseracing Authority. $\mathrm{JH}$ is employed by the British Horseracing Authority. MSS is supported by the NIHR Biomedical Research Centre at the University of Oxford.

Patient and public involvement Patients and/or the public were involved in the design, or conduct, or reporting, or dissemination plans of this research. Refer to the Methods section for further details.

Patient consent for publication Not required.

Ethics approval This study has received ethical approval from the University of Oxford Central University Research Ethics Committee (MS-IDREC-CX-2014-147).

Provenance and peer review Not commissioned; externally peer reviewed.

Data availability statement № data are available. No novel datasets were generated during the current study. Anonymised injury data analysed in this study were made available by the named collaborators for the purpose of this analysis and ownership is retained by those collaborating organisations.

Open access This is an open access article distributed in accordance with the Creative Commons Attribution Non Commercial (CC BY-NC 4.0) license, which permits others to distribute, remix, adapt, build upon this work non-commercially, and license their derivative works on different terms, provided the original work is properly cited, appropriate credit is given, any changes made indicated, and the use is non-commercial. See: http://creativecommons.org/licenses/by-nc/4.0/.

\section{ORCID iDs}

Madeleine Davies http://orcid.org/0000-0002-6047-7340

Maria Sanchez Santos http://orcid.org/0000-0003-1908-8623

\section{REFERENCES}

1 . Returning safely - British racing goes back to work - key points British Horseracing Authority; 2020. http://media.britishhorseracing. com/bha/covid19/Resumption_key_points.pdf

2 Turner M, Balendra G, McCrory P. Payments to injured professional jockeys in British horse racing (1996-2006). Br J Sports Med 2008;42:763-6.

3 Curry BA, Hitchens PL, Otahal P, et al. Workplace injuries in thoroughbred racing: an analysis of insurance payments and injuries amongst jockeys in Australia from 2002 to 2010. Animals 2015;5:897-909.
4 Curry BA, Hitchens PL, Otahal P, et al. Australian insurance costs of jockeys injured in a race-day fall. Occup Med 2016;66:222-9.

5 Rueda MAF, Halley WL, Gilchrist MD. Fall and injury incidence rates of jockeys while racing in Ireland, France and Britain. Injury 2010;41:533-9.

6 Hitchens PL, Hill AE, Stover SM. Jockey falls, injuries, and fatalities associated with thoroughbred and quarter horse racing in California 2007-2011. Orthop J Sports Med 2013;1:232596711349262.

7 Press JM, Davis PD, Wiesner SL, et al. The National jockey injury study: an analysis of injuries to professional horse-racing jockeys. Clin J Sport Med 1995;5:236-40.

8 McCrory Pet al. An analysis of injuries resulting from professional horse racing in France during 1991-2001: a comparison with injuries resulting from professional horse racing in Great Britain during 19922001. Br J Sports Med 2006;40:614-8.

9 Waller AE, Daniels JL, Weaver NL, et al. Jockey injuries in the United States. JAMA 2000;283:1326

10 Wylie CE, McManus P, McDonald C, et al. Thoroughbred fatality and associated jockey falls and injuries in races in New South Wales and the Australian Capital Territory, Australia: 2009-2014. Vet J 2017;227:1-7.

11 Yim VWT, Yeung JHH, Mak PSK, et al. Five year analysis of Jockey Club horse-related injuries presenting to a trauma centre in Hong Kong. Injury 2007;38:98-103.

12 Bolwell C, Rogers C, Gee E. Descriptive epidemiology of raceday jockey falls and injuries in New Zealand. Comp Exerc Physiol 2014;10:49-55.

13 Balendra G, Turner M, McCrory P. Career-ending injuries to professional jockeys in British horse racing (1991-2005). Br J Sports Med 2008;42.

14 O'Connor S, Warrington G, McGoldrick A. Epidemiology of injury due to race-day jockey falls in professional flat and jump horse racing in Ireland, 2011 -2015. J Athl Train 2017.

15 Turner M, McCrory P, Halley W. Injuries in professional horse racing in Great britain and the Republic of Ireland during 1992-2000. Br J Sports Med 2002;36:403-9.

16 Jackson KA, Sanchez-Santos MT, MacKinnon AL, et al. Bone density and body composition in newly licenced professional jockeys. Osteoporos Int 2017;28:2675-82.

17 Bahr R, Clarsen B, Derman W. International Olympic Committee consensus statement : methods for recording and reporting of epidemiological data on injury and illness in sport 2020 (including STROBE Extension for Sport Injury and Illness Surveillance (STROBE- SIIS)). Br J Sports Med 2020;8:1-18.

18 Rae K, Orchard J. The orchard sports injury classification system (OSICS) version 10. Clin J Sport Med 2007;17:201-4.

19 Von Elm E, Altman DG, Egger M. The strengthening the reporting of observational studies in epidemiology (STROBE) statement: guidelines for reporting observational studies. PLoS Med 2007

20 Legg KA, Cochrane DJ, Bolwell CF, et al. Incidence and risk factors for race-day jockey falls over fourteen years. J Sci Med Sport 2020;23:1154-60.

21 Hitchens PL, Morrice-West AV, Stevenson MA, et al. Meta-Analysis of risk factors for racehorse catastrophic musculoskeletal injury in flat racing. Vet $J$ 2019;245:29-40.

22 Mountjoy M, Sundgot-Borgen J, Burke L, et al. The IOC consensus statement: beyond the Female Athlete Triad--Relative Energy Deficiency in Sport (RED-S). Br J Sports Med 2014;48:491-7.

23 Wilson G, Hill J, Martin D, et al. Gb apprentice jockeys do not have the body composition to make current minimum race weights: is it time to change the weights or change the jockeys? Int J Sport Nutr Exerc Metab 2020:101-4.

24 Fuller CW, Molloy MG, Bagate C, et al. Consensus statement on injury definitions and data collection procedures for studies of injuries in rugby Union. Br J Sports Med 2007;41:328-31.

25 Bahr R, Clarsen B, Derman W, et al. International Olympic Committee consensus statement: methods for recording and reporting of epidemiological data on injury and illness in sport 2020 (including STROBE extension for sport injury and illness surveillance (STROBESIIS)). Br J Sports Med 2020;54:372-89.

26 Turner M, Balendra G, McCrory P. Payments to injured professional jockeys in British horse racing (1996-2006). Br J Sports Med 2008;42:763-6.

27 Hitchens P, Blizzard L, Jones G. Are physiological attributes of jockeys predictors of falls? A pilot study. BMJ Open 2014;1:1-7.

28 Hitchens PL, Blizzard CL, Jones G, et al. The incidence of race-day jockey falls in Australia, 2002-2006. Med J Aust 2009;190:83-6.

29 O'Connor S, Warrington G, McGoldrick A, et al. Race day concussion incidence in Irish professional flat and jump horse racing from 2011 to 2016. J Sci Med Sport 2017;20:20-1. 